Special Issue of the 8th International Advances in Applied Physics and Materials Science Congress (APMAS 2018)

\title{
Biodegradable Hydrogels based on Acrylamide, Acrylic Acid and Sodium Alginate Synthesized by Electron Beam Irradiation
}

\author{
E. Manaila and G. Craciun* \\ National Institute for Laser, Plasma and Radiation Physics, Electron Accelerators Laboratory, \\ 409 Atomistilor St., 077125 Magurele, Romania

\begin{abstract}
The poly(acrylamide co-acrylic acid) — sodium alginate hydrogels for heavy metal removal were prepared by electron beam irradiation using the $5.5 \mathrm{MeV}$ electron beam accelerator, ALID-7. The irradiation dose was between $1.9 \mathrm{kGy}$ and $9.5 \mathrm{kGy}$ and the influence on the swelling properties was investigated. The hydrogels were tested for heavy metal removal in uptake experiments made on aqueous solutions of 635 and $1270 \mathrm{ppm} \mathrm{Cu}^{2+}$, respectively. The absorption of $\mathrm{Cu}^{2+}$ ions was over $400 \mathrm{mg} / \mathrm{g}$ and $120 \mathrm{mg} / \mathrm{g}$, respectively.
\end{abstract}

DOI: 10.12693/APhysPolA.135.1063

PACS/topics: acrylamide, sodium alginate, irradiation, properties, heavy metal

\section{Introduction}

Hydrogels are macromolecular networks able to absorb and release water solutions in a reversible manner [1]. Usually, most hydrogels are prepared from synthetic polymers by radical copolymerization, frontal copolymerization, graft copolymerization or cross-linking [2]. Recently, several available works dealing with the preparation of hydrogels based on both synthetic and natural polymers [3, 4]. Electron beam (EB) irradiation of aqueous solutions containing appropriate monomer mixtures was used to prepared polymeric materials for wastewater treatment, agriculture or medicine [5]. The goal of the paper is to present the obtaining and characterization of a new type of superabsorbent hydrogel based on acrylamide, acrylic acid and sodium alginate having the potential use for heavy metal removal.

\section{Materials and equipments}

Every sample containing $0.1 \mathrm{~g}$ of sodium alginate dissolved in $3 \mathrm{~mL}$ of distilled water and mixed with $1 \mathrm{~g}$ of acrylamide and $0.95 \mathrm{~mL}$ acrylic acid was irradiated in atmospheric conditions and at room temperature of $25^{\circ} \mathrm{C}$, using the linear electron accelerator of $5.5 \mathrm{MeV}$, ALID 7. The EB dose rate was of $2 \mathrm{kGy} / \mathrm{min}$ in order to accumulate doses between 1.9 and $9.5 \mathrm{kGy}$. The obtained hydrogels were cuted in small pieces and dried out until the constant weight. The metal ion uptake experiments were carried out by immersion of $0.02 \mathrm{~g}$ of each dried hydrogels in $40 \mathrm{~mL}$ of distilled water containing various concentrations of $\mathrm{Cu}^{2+}$ ions for 24 and $48 \mathrm{~h}$, at room temperature of $25^{\circ} \mathrm{C}$. Two types of copper based solutions were realized using $\mathrm{CuSO}_{4} \cdot 5 \mathrm{H}_{2} \mathrm{O}$ and distilled water. Using $2.496 \mathrm{~g} / \mathrm{L}$ and $4.992 \mathrm{~g} / \mathrm{L}$, the resulting $\mathrm{Cu}^{2+}$ concentrations in water solutions were of 635 and $1270 \mathrm{ppm}$ respectively.

\section{Results and discussion}

The gel content, degree of swelling, equilibrium water content, diffusion parameters and network studies were performed according to previous studies [6]. The gel content in hydrogel increases with the irradiation dose as it can be seen in Fig. 1a. Swelling isotherms of hydrogels are shown in Fig. 1b.
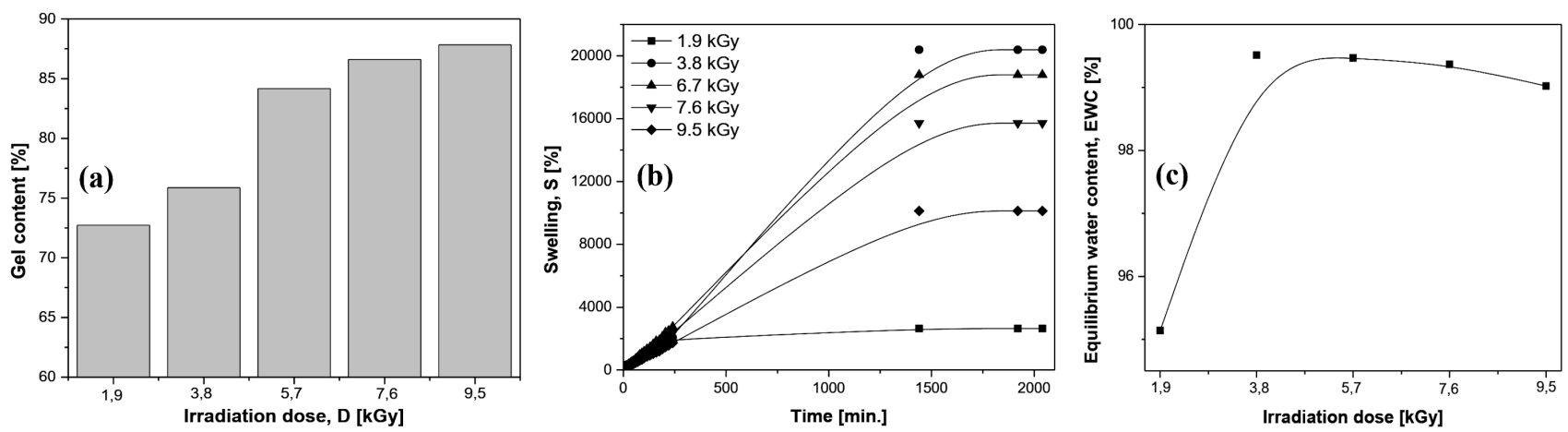

Fig. 1. The properties of hydrogels as a function of irradiation dose: (a) gel content, (b) swelling degree and (c) equilibrium water content.

*corresponding author; e-mail: gabriela.craciun@inflpr.ro 
The degree of swelling decreased with the irradiation dose increasing, excepting for the irradiation dose of $1.9 \mathrm{kGy}$. The best degree of swelling had the hydrogels obtained at $3.8 \mathrm{kGy}$, being almost $20000 \%$. As it can be seen from Fig. 1c, the hydrogels have reached the equilibrium water content (EWC [\%]) over $99 \%$ starting with $3.8 \mathrm{kGy}$.

The amount of metal ion adsorbed $(Q)$ was calculated according to previous studies $[7,8]$. The $\mathrm{Cu}^{2+}$ absorption results after 24 and $48 \mathrm{~h}$ are presented in Fig. 2.
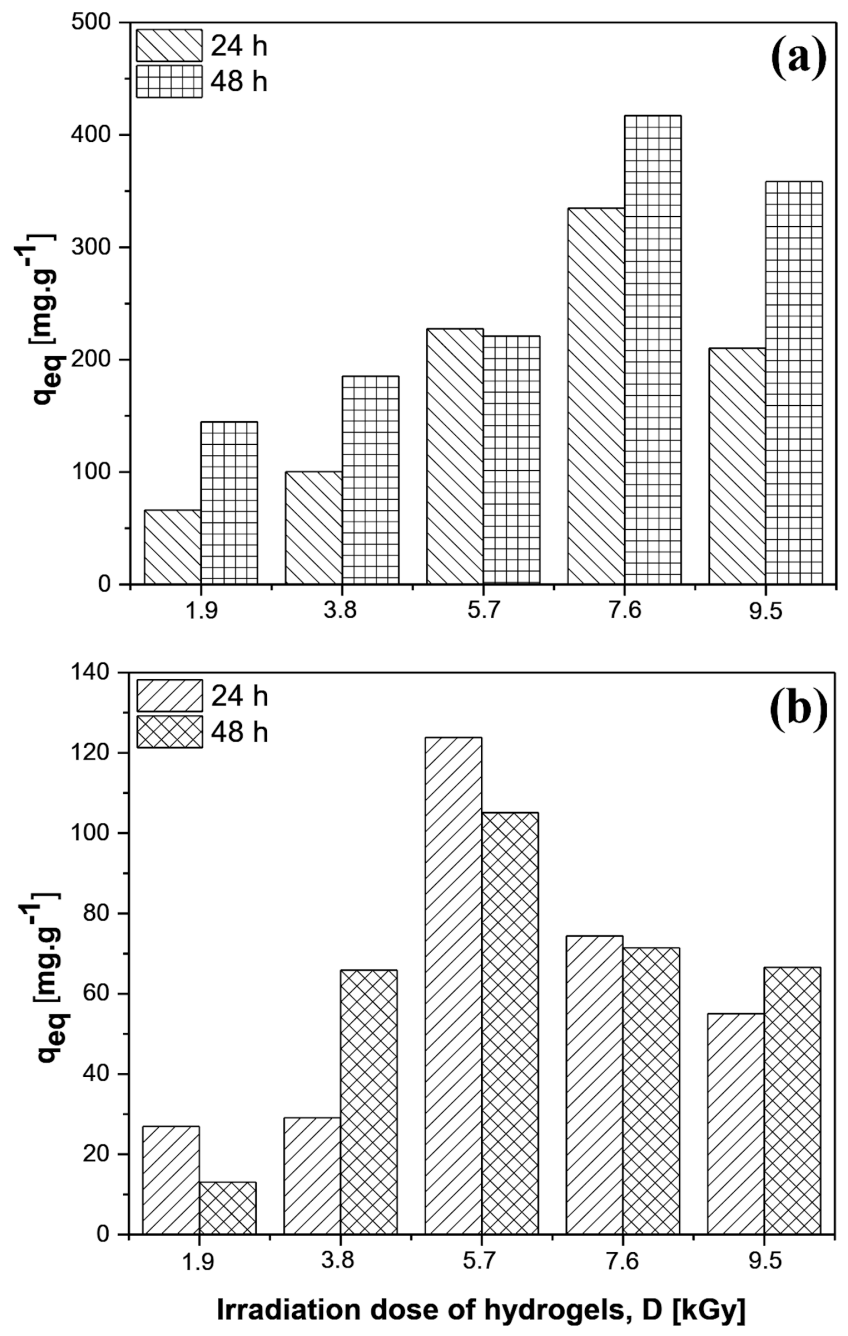

Fig. 2. The adsorbed amount of heavy metal ions versus electron beam irradiation dose: (a) $635 \mathrm{ppm} \mathrm{Cu}^{2+}$ and (b) $1270 \mathrm{ppm} \mathrm{Cu}^{2+}$.
Hydrogels were more efficient for $\mathrm{Cu}^{2+}$ ions removal from the less concentrated solution of $635 \mathrm{ppm}$ and less efficient for $\mathrm{Cu}^{2+}$ ions removal from the more concentrated solution of $1270 \mathrm{ppm}$, the maximum of $125 \mathrm{mg} / \mathrm{g}$ being obtained at $5.7 \mathrm{kGy}$.

\section{Conclusion}

A new type of superabsorbent hydrogel based on acrylamide, acrylic acid and sodium alginate was obtained by free-radical copolymerization reaction in electron beam of $5.5 \mathrm{MeV}$. The swelling properties, diffusion coefficient and network parameters of the hydrogels are improved by the obtaining maethod. Uptake experiments on aqueous solutions of 635 and $1270 \mathrm{ppm} \mathrm{Cu}^{2+}$ were made. The amount of heavy metal ions adsorbed from the solution of $635 \mathrm{ppm}$ after $48 \mathrm{~h}$ was over $400 \mathrm{mg} / \mathrm{g}$. The hydrogels were less efficient for $\mathrm{Cu}^{2+}$ ions removal from the more concentrated solution of $1270 \mathrm{ppm}$.

\section{Acknowledgments}

The researches were financed by the Romanian program NUCLEU - Contract No. 18.13.01.02.

\section{References}

[1] A. Sannino, C. Demitri, M. Madaghiele, Materials 2 , 353 (2009).

[2] C. Chang, B. Duan, J. Cai, L. Zhang, Eur. Polym. J. 46, 92 (2010).

[3] T.P. Kraehenbuehl, P. Zammaretti, A.J. Van der Vlies, R.G. Schoenmakers, M.P. Lutolf, M.E. Jaconi, J.A. Hubbel, Biomaterials 29, 2757 (2008).

[4] C. Chang, B. Duan, L. Zhang, Polymer 50, 5467 (2009).

[5] M. Sadeghi, F. Shafiei, E. Mohammadi Nasab, Orient. J. Chem. 28, 1729 (2012)

[6] E. Manaila, G. Craciun, D. Ighigeanu, C. Cimpeanu, C. Barna, V. Fugaru, Materials 10, 450 (2017).

[7] K.T. Vadiraj, S.L. Belegali, Bulgarian Chem. Communicat. 46, 447 (2014).

[8] M.A. Shouman, N.A. Fathy, S.A. Khedr, A.A. Attia, Adv. Physi. Chem. 2013, 159712 (2013). 